\title{
Role of the Clinical Standards Advisory Group
}

\author{
Gordon Higginson
}

What is the Clinical Standards Advisory Group? Its genesis lay in discussions between the royal colleges and other professional organisations about concerns they had over the possible effects of the health service reforms on clinical standards. Its terms of reference are to advise on standards of clinical care and access and availability of services to patients, whether they are in NHS units or in private hospitals. The Clinical Standards Advisory Group was written into the NHS and Community Care Act of 1990, set up in the middle of last year, and was given its first remits early this year.

Who are the group's members?

The group is appointed by ministers, and I am its "independent lay chairman." I hope that I'm independent at times, and I am certainly very lay. Eight members of the group are nominated by the Conference of the Medical Royal Colleges and their Faculties, four by the Royal College of Nursing and the Royal College of Midwives, and one by the Faculty of Dental Surgery. Ex officio members include the chairmen of the Standing Dental Advisory Committee, the Standing Medical Advisory Committee, and the Standing Nursing and Midwifery Advisory Committee. There are also observers nominated by the presidents of the General Dental Council; the General Medical Council; and the United Kingdom Central Council for Nursing, Midwifery, and Health Visitors and observers from the Joint Consultants Committee and the General Medical Services Committee of the BMA. The four chief medical officers of the United Kingdom, the chief nursing officer, and the chief dental officer also attend as observers. Anyone who has seen the membership will agree, I think, that the group's members are an awesome lot. I am tempted to quote the overworked: "I don't know what they do to the enemy, but by God they frighten me", but I shall not, partly because they don't - in fact they are very kind and gentle - but primarily because the last thing we want is enemies. The group is totally dependent on genuine and wholehearted collaboration with clinicians. Its members must be seen as colleagues in this business, working with common aims, and we must avoid, at all costs, what Don Berwick would describe as the threat of being watched. Also, unlike the Audit Commission, the Clinical Standards Advisory Group has no statutory powers of access to records. It has an interface with the Audit Commission, and I hope that we shall be able to cooperate in some way, perhaps even tackle some joint projects, but the group has a different statutory basis.

\section{How will the group operate?}

The group is advisory - that, of course, is in its title. It will also be visitorial in that its members will get about. Not as the whole group, of course - we would need a jumbo jet to take us all together - but in small subgroups. The group will submit reports to health ministers and has an undertaking that these would normally be published and would receive a published response from the ministers - that is, the secretaries of state for health, Scotland, Wales, and Northern Ireland.

\section{Emphasising the multidisciplinary approach}

The group are expected to offer multidisciplinary advice, and it is accepted that the group will not cut across established channels of communication nor duplicate the functions of existing bodies such as the royal colleges. I think the group needs to emphasise its multidisciplinary nature to avoid treading on too many unidisciplinary toes.

For each project the group will set up a team consisting of members of the group plus co-opted clinicians and, when appropriate, researchers. Between them these groups will gather information from a sample of NHS units and other sources, as appropriate, using existing information when available. The method of working must ensure confidentiality and anonymity.

So far the group has embarked on four remits (box), and there are others in the pipeline. The first is access to and availability of four selected specialist services. That entails separate working parties for each of those four specialist services. The second remit is urgent and emergency admissions to hospital, the third is services to people with diabetes, and the fourth is the management of normal labour in maternity wards. These remits are set out

Remits of Clinical Standards Advisory
Group
Access to and availability of specialist services
- neonatal intensive care
- childhood leukaemia
- cystic fibrosis
- coronary artery bypass grafting
Urgent and emergency admissions to hospital
Diabetes services
Management of normal labour


and discussed in more detail elsewhere. ${ }^{12}$ They were anounced by the secretary of state, but they were, I should say, all suggested by the group.

\section{Standards}

The group will make use of standards set by the professions. There may be occasions when the standards will emerge from its projects and the professional discussions that follow its reports - but it is not the group's business to set standards. When I read through Don Berwick's principles it was clear to me that they apply equally well to engineering and education - my main concerns. In engineering and education we distinguish between quality and standards but are inclined to talk about fitness for a purpose. In education a course can be of high standard but poor quality. I suspect that many of you have been on such courses. It is also possible to run courses of low standard and high quality. A friend of mine gave a quite prestigious course of lectures for which he received a substantial fee. So he decided to spoil himself and buy a very high quality watch. He bought himself a famous make at enormous expense. It was a beautiful piece of engineering, made with great precision, but it was not perfectly accurate. $\mathrm{He}$ found it lost about five seconds a month. Soon afterwards he acquired a digital watch in a black plastic case. It was a promotional gift with petrol bought at a garage, but he could probably have bought it for about two pounds anyway. He found it actually a better time keeper than the expensive watch. That is what engineers mean by "fitness for purpose." In health care, as standards rise so will expectations; and that seems to me to be the grand challenge to the health professions.

1 Written answer. Clinical Standards Advisory Group. House of Commons Official Repon (Hansard) 1992 Jan 16;201:col 627. (No 41.)

2 Higginson G. Functions of the Clinical Standards Advisory Group (letter). BMJ 1992;304:571. 